\title{
Behind a personalized therapy with immune check-point inhibitors in metastatic bladder cancer: ready for a primetime?
}

\author{
Sławomir Poletajew ${ }^{1}$, Wojciech Krajewski ${ }^{2}$, Piotr Kryst ${ }^{1}$ \\ ${ }^{1}$ Second Department of Urology, Centre of Postgraduate Medical Education, Warsaw, Poland; ${ }^{2}$ Department of Urology and Oncological Urology, \\ Wrocław Medical University, Wrocław, Poland \\ Correspondence to: Sławomir Poletajew, MD, PhD, FEBU. Second Department of Urology, Centre of Postgraduate Medical Education, 80 Cegłowska \\ St., 00809 Warsaw, Poland. Email: slawomir.poletajew@cmkp.edu.pl. \\ Comment on: Witjes JA, Babjuk M, Bellmunt J, et al. EAU-ESMO consensus statements on the management of advanced and variant bladder cancer- \\ an international collaborative multistakeholder effort $†$ : under the auspices of the EAU-ESMO Guidelines Committees. Eur Urol 2020;77:223-50.
}

Submitted May 02, 2020. Accepted for publication Jun 19, 2020.

doi: $10.21037 /$ tau-20-907

View this article at: http://dx.doi.org/10.21037/tau-20-907

Immune check-point inhibitors (ICIs) for the treatment of patients with urothelial carcinoma are recently under extensive research. Until now, the strongest evidence concerns advanced metastatic cases. In this setting, ICIs can be used as a first-line therapy in cisplatin-ineligible patients or as a second-line therapy in patients progressing after cisplatin-based systemic therapy (1). However, limitations of published studies, effectiveness in a limited patient populations, drug accelerated registrations based on phase II studies, novel phenomena in the course of treatment, different safety profiles and many other aspects make us careful in drawing clinical conclusions and dampen enthusiasm associated with a novel therapeutic option in this field of "no progress for many years". We read with great interest recent EAU-ESMO consensus statements in the management of advanced and variant bladder cancer (2). In a great part of the document, experts address important and actual clinical problems related to ICIs. Experts correctly point to the most pressing problems in this field, namely the phenomenon of pseudo-progression (PP), predictive biomarkers and the role of conventional chemotherapy in this new therapeutic era. As we agree with rationale behind presented statements, we think that some of them need further discussion.

\section{Pseudo-progression}

Research on ICIs have indicated a novel phenomenon of radiological disease progression followed by objective response to treatment, so called PP. As this had required reclassification of the RECIST criteria, novel classifications were proposed: immune-related response criteria (irRC) and iRECIST $(3,4)$. In the EAU-ESMO consensus statements in the management of advanced and variant bladder cancer, experts summarize that the phenomenon of PP has not been demonstrated in urothelial cancer (2).

As this statement questions the role of above-mentioned radiological classifications in patients with bladder cancer and may lead to diagnosis of disease progression in some patients, we should carefully look back into Imvigor-211 and Checkmate-275 studies. As summarized by Soria et al., PP was observed in $1.5-17 \%$ of urothelial cancer patients treated with atezolizumab or nivolumab (5). Apart from phase II clinical trials included in the systematic review, PP can also be noticed in everyday clinical practice in patients treated with durvalumab (6). This data clearly stands in opposition to what EAU-ESMO experts state. Simultaneously, so far, no report on PP phenomenon in pembrolizumab or avelumab treated patients was reported.

\section{Biomarkers}

We agree with EAU-ESMO experts, that the variability in methods used to assess PD-L1 status for different ICIs impedes clinical judgement and may affect the outcomes. However, despite PD-L1 status seems imperfect in personalizing therapy with ICIs, EMA and FDA recommend its use and restricts ICIs as a first-line therapy only to PD-L1 positive patients (7). These regulations result from a significantly higher response rate (RR) observed for 
PD-L1 positive patients $(8,9)$.

We are all aware that responses to ICIs are seen in a limited group of patients. Moreover, we must admit that there is no valuable and validated alternative to PD-L1 status as a predictive tool. However, several interesting alternative biomarkers are currently under research and our attitude may change in close future.

Firstly, the load of mutations and neoantigens is not only a key element for ICIs mechanism of action in urothelial cancer (10), but it was also demonstrated as a possible predictor of response to therapy in lung cancer and melanoma (11-17). Moreover, it was shown that mismatch repair (MMR) deficiency is associated with the presence of tumor-infiltrating T-cells and high PD-L1 expression (18). Further studies revealed the prognostic value of MMR deficiency in patients treated with ICIs for colorectal cancer, endometrial cancer, gastroesophageal cancer, neuroendocrine tumors, osteosarcoma, pancreatic cancer, prostate cancer, small intestine cancer, thyroid cancer, cholangiocarcinoma $(19,20)$. Moreover, in melanoma patients few gene expression signatures were reported as associated with response to ICIs (21-24). As urothelial cancer is a highly heterogeneous entity in terms of somatic mutations, this aspect urgently needs investigation.

Secondly, many research groups focused on identification of a single gene mutation of predictive value. Among many published studies, only two concerned urothelial cancer patients. Teo et al. showed that alterations in any gene associated with DNA damage response pathway (ATM, POLE, BRCA2, ERCC2, FANCA, MSH6, FAK1, JAK2, $B 2 M)$ are associated with higher RR to nivolumab and atezolizumab among patients with advanced urothelial cancer (25). On the other hand, Kato et al. found that $E G F R$ gene aberrations and $M D M$ gene amplification are associated with increased risk of progression in ICIs treated patients with bladder, breast and lung cancer (26).

Finally, the presence of PD-1 tumor infiltrative T-cells (TIL) was proposed as another possible biomarker. High TIL was already reported as a predictor of improved RR to ICIs and improved survival in melanoma, colorectal and breast cancer $(27,28)$. Interestingly, also non-invasive methods to assess the presence of PD-1 tumor infiltrative T-cells were proposed in animal and clinical studies (29-31).

\section{ICIs in cisplatin-ineligible patients}

Enthusiasm regarding ICIs cannot be adequately explained regarding first-line treatment in cisplatin-ineligible patients. The only available data come from phase I study Javelin or phase II studies Keynote-052 and Imvigor-210 (32-34). In this setting, RRs noticed for pembolizumab (24\%) and atezolizumab (23\%) are significantly lower than RRs for gemcitabine-carboplatin chemotherapy (28-56\%) (35). However, these numbers do not come from head-to-head comparative studies, so oncological community is awaiting results of phase III studies for final conclusions. We agree with Authors that today, even in PD-L1 positive patients, it is not justified to favor ICI over Gem-Carbo chemotherapy.

\section{Acknowledgments}

Funding: None.

\section{Footnote}

Provenance and Peer Review: This article was commissioned by the editorial office, Translational Andrology and Urology. The article did not undergo external peer review.

Conflicts of Interest: All authors have completed the ICMJE uniform disclosure form (available at http://dx.doi. org/10.21037/tau-20-907). The authors have no conflicts of interest to declare.

Ethical Statement: The authors are accountable for all aspects of the work in ensuring that questions related to the accuracy or integrity of any part of the work are appropriately investigated and resolved.

Open Access Statement: This is an Open Access article distributed in accordance with the Creative Commons Attribution-NonCommercial-NoDerivs 4.0 International License (CC BY-NC-ND 4.0), which permits the noncommercial replication and distribution of the article with the strict proviso that no changes or edits are made and the original work is properly cited (including links to both the formal publication through the relevant DOI and the license). See: https://creativecommons.org/licenses/by-nc-nd/4.0/.

\section{References}

1. European Association of Urology. Compilations of all Guidelines. Available online: http://uroweb.org/guidelines/ compilations-of-all-guidelines/

2. Witjes JA, Babjuk M, Bellmunt J, et al. EAU-ESMO 
consensus statements on the management of advanced and variant bladder cancer-an international collaborative multistakeholder effort + : under the auspices of the EAUESMO Guidelines Committees. Eur Urol 2020;77:223-50.

3. Wolchok JD, Hoos A, O'Day S, et al. Guidelines for the evaluation of immune therapy activity in solid tumors: immune-related response criteria. Clin Cancer Res 2009;15:7412-20.

4. Seymour L, Bogaerts J, Perrone A, et al. iRECIST: guidelines for response criteria for use in trials testing immunotherapeutics. Lancet Oncol 2017;18:e143-52.

5. Soria F, Beleni AI, D'Andrea D, et al. Pseudoprogression and hyperprogression during immune checkpoint inhibitor therapy for urothelial and kidney cancer. World J Urol 2018;36:1703-9.

6. Kim EY, Park I, Kim YS, et al. Unusual radiologic manifestation of pseudoprogression in pulmonary metastases after durvalumab treatment in metastatic bladder urothelial cancer. Thorac Cancer 2019;10:1016-8.

7. Eckstein M, Cimadamore A, Hartmann A, et al. PD-L1 assessment in urothelial carcinoma: a practical approach. Ann Transl Med 2019;7:690.

8. Fan Z, Liang Y, Yang X, et al. A meta-analysis of the efficacy and safety of PD-1/PD-L1 immune checkpoint inhibitors as treatments for metastatic bladder cancer. Onco Targets Ther 2019;12:1791-801.

9. Rui X, Gu TT, Pan HF, et al. Evaluation of PD-L1 biomarker for immune checkpoint inhibitor (PD-1/PD-L1 inhibitors) treatments for urothelial carcinoma patients: a meta-analysis. Int Immunopharmacol 2019;67:378-85.

10. Alexandrov LB, Nik-Zainal S, Wedge DC, et al. Signatures of mutational processes in human cancer. Nature 2013;500:415-21.

11. McGranahan N, Furness AJ, Rosenthal R, et al. Clonal neoantigens elicit $\mathrm{T}$ cell immunoreactivity and sensitivity to immune checkpoint blockade. Science 2016;351:1463-9.

12. Snyder A, Makarov V, Merghoub T, et al. Genetic basis for clinical response to CTLA-4 blockade in melanoma. $\mathrm{N}$ Engl J Med 2014;371:2189-99.

13. Rizvi NA, Hellmann MD, Snyder A, et al. Cancer immunology. Mutational landscape determines sensitivity to PD-1 blockade in non-small cell lung cancer. Science 2015;348:124-8.

14. Hellmann MD, Ciuleanu TE, Pluzanski A, et al. Nivolumab plus ipilimumab in lung cancer with a high tumor mutational burden. N Engl J Med 2018;378:2093-104.

15. Gandara DR, Paul SM, Kowanetz M, et al. Bloodbased tumor mutational burden as a predictor of clinical benefit in non-small-cell lung cancer patients treated with atezolizumab. Nat Med 2018;24:1441-8.

16. Campesato LF, Barroso-Sousa R, Jimenez L, et al. Comprehensive cancer-gene panels can be used to estimate mutational load and predict clinical benefit to PD-1 blockade in clinical practice. Oncotarget 2015;6:34221-7.

17. Hellmann MD, Callahan MK, Awad MM, et al. Tumor mutational burden and efficacy of nivolumab monotherapy and in combination with ipilimumab in small-cell lung cancer. Cancer Cell 2018;33:853-61.e4.

18. Yamashita H, Nakayama K, Ishikawa M, et al. Microsatellite instability is a biomarker for immune checkpoint inhibitors in endometrial cancer. Oncotarget 2017;9:5652-64.

19. Le DT, Uram JN, Wang H, et al. PD-1 Blockade in tumors with mismatch-repair deficiency. N Engl J Med 2015;372:2509-20.

20. Le DT, Durham JN, Smith KN, et al. Mismatch repair deficiency predicts response of solid tumors to PD-1 blockade. Science 2017;357:409-13.

21. Spranger S, Bao R, Gajewski TF. Melanoma-intrinsic $\beta$-catenin signalling prevents anti-tumour immunity. Nature 2015;523:231-5.

22. Ayers M, Lunceford J, Nebozhyn M, et al. IFN- $\gamma$-related mRNA profile predicts clinical response to PD-1 blockade. J Clin Invest 2017;127:2930-40.

23. Mullane SA, Werner L, Rosenberg J, et al. Correlation of Apobec Mrna expression with overall survival and pd-11 expression in urothelial carcinoma. Sci Rep 2016;6:27702.

24. Auslander N, Zhang G, Lee JS, et al. Robust prediction of response to immune checkpoint blockade therapy in metastatic melanoma. Nat Med 2018;24:1545-9.

25. Teo MY, Seier K, Ostrovnaya I, et al. Alterations in DNA damage response and repair genes as potential marker of clinical benefit from PD-1/PD-L1 blockade in advanced urothelial cancers. J Clin Oncol. 2018;36:1685-94.

26. Kato S, Goodman A, Walavalkar V, et al. Hyperprogressors after immunotherapy: analysis of genomic alterations associated with accelerated growth rate. Clin Cancer Res 2017;23:4242-50.

27. Denkert C, von Minckwitz G, Darb-Esfahani S, et al. Tumour-infiltrating lymphocytes and prognosis in different subtypes of breast cancer: a pooled analysis of 3771 patients treated with neoadjuvant therapy. Lancet Oncol 2018;19:40-50.

28. Hamada T, Soong TR, Masugi Y, et al. TIME (Tumor Immunity in the MicroEnvironment) classification based on tumor CD274 (PD-L1) expression status and 
tumor-infiltrating lymphocytes in colorectal carcinomas. Oncoimmunology 2018;7:e1442999.

29. Bensch F, van der Veen EL, Lub-de Hooge MN, et al. $89 \mathrm{Zr}$-atezolizumab imaging as a non-invasive approach to assess clinical response to PD-L1 blockade in cancer. Nat Med 2018;24:1852-8.

30. Natarajan A, Mayer AT, Xu L, et al. Novel radiotracer for immunoPET imaging of PD-1 checkpoint expression on tumor infiltrating lymphocytes. Bioconjug Chem 2015;26:2062-9.

31. Chatterjee S, Lesniak WG, Gabrielson M, et al. A humanized antibody for imaging immune checkpoint ligand PD-L1 expression in tumors. Oncotarget 2016;7:10215-27.

32. Patel MR, Ellerton J, Infante JR, et al. Avelumab in metastatic urothelial carcinoma after platinum failure (JAVELIN Solid Tumor): pooled results from two

Cite this article as: Poletajew S, Krajewski W, Kryst P. Behind a personalized therapy with immune check-point inhibitors in metastatic bladder cancer: ready for a primetime? Transl Androl Urol 2020;9(6):2479-2482. doi: 10.21037/tau-20-907 expansion cohorts of an open-label, phase 1 trial. Lancet Oncol 2018;19:51-64.

33. Balar AV, Castellano D, O'Donnell PH, et al. First-line pembrolizumab in cisplatin-ineligible patients with locally advanced and unresectable or metastatic urothelial cancer (KEYNOTE-052): a multicentre, single-arm, phase 2 study. Lancet Oncol 2017;18:1483-92.

34. Balar AV, Galsky MD, Rosenberg JE, et al. Atezolizumab as first-line treatment in cisplatin-ineligible patients with locally advanced and metastatic urothelial carcinoma: a single-arm, multicentre, phase 2 trial. Lancet 2017;389:67-76.

35. Galsky MD, Chen GJ, Oh WK, et al. Comparative effectiveness of cisplatin-based and carboplatin-based chemotherapy for treatment of advanced urothelial carcinoma. Ann Oncol 2012;23:406-10. 